\title{
Modeling of single phase off-grid inverter for small standalone system applications
}

\author{
Rodney H. G. Tan, Chong Boon Chuin, Sunil Govinda Solanki
}

Department of Electrical and Electronic Engineering, UCSI University, Malaysia

\begin{tabular}{l}
\hline \hline Article Info \\
\hline Article history: \\
Received Feb 9, 2020 \\
Revised Mar 31, 2020 \\
Accepted Apr 21, 2020 \\
\hline
\end{tabular}

Keywords:

Off-grid inverter

Commerical inverter

Standalone system

Photovoltaic system

Battery system

\begin{abstract}
This paper presents the detail circuitry modeling of single phase off-grid inverter for small standalone system applications. The entire model is developed in MATLAB/Simulink platform using circuitry model. This off grid inverter consists of a high frequency DC-DC step up converter cascaded with a full bridge PI control voltage source inverter using SPWM modulation with LC filter to produce sine wave output. This is a common design used in many small commercial off-grid inverter. This off-grid inverter model is capable to produce AC sinewave output voltage at $230 \mathrm{~V} 50 \mathrm{~Hz}$ up to $1 \mathrm{~kW}$ power from a $48 \mathrm{~V} \mathrm{DC}$ lead acid battery source. The AC sine wave output waveform achieved a voltage Total Harmonic Distortion (THD) of less than $1 \%$ which is almost a pure sine wave. The conversion efficiency performance of the off-grid inverter achieved more than $94 \%$. The performance of the model is validated by real commercial off-grid inverter. The performance validation experiment shows that the off-grid inverter Simulink model conversion efficiency and THD performance are comparable to the commercial off-grid inverter. This model contributes to assist small to medium standalone system load and battery sizing design with greater accuracy.
\end{abstract}

This is an open access article under the CC BY-SA license.

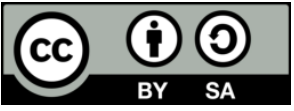

\section{Corresponding Author:}

Rodney H.G. Tan,

Departement of Electrical and Electronic Engineering,

UCSI University,

No.1, Jalan Menara Gading, Taman Connaught, 56000 Kuala Lumpur, Malaysia.

Email: rodneytan@ucsiuniversity.edu.my

\section{INTRODUCTION}

In the past decade solar photovoltaic renewable energy has gained an exponential growth around the globe up to $181 \mathrm{GW}$ installed worldwide as of the end of 2018 [1]. The is because the ease of installation and less maintenance due to no moving part involves in the photovoltaic system, besides that, the cost of the photovoltaic system has been reduced significantly throughout the years are that major factors that favour photovoltaic system as popular choices in the renewable energy industry. Power inverter is a power electronics converter that converts DC input voltage to AC output voltage with controlled output voltage magnitude and frequency. The inverter plays an important role in the renewable energy chain, it is an indispensable parts of solar photovoltaic and battery energy storage system. Inverter has basically divided into three distinct categories, there are grid connected inverter, off-grid inverter and On/Off Grid Tie Inverter. Each inverter has there are own challenges. The off-grid inverter basically uses in standalone system, the main challenges are to step up low DC battery voltage to AC supply voltage level in either single or three phase. It must be capable to maintain the AC output voltage magnitude and frequency under various load conditions within it rated power capacity. On the other hand, the grid connected inverter requires 
the synchronization of phase, frequency and magnitude with the utility grid in either single or three phase. Apart of grid synchronization, it is also required to control the delivery of real and reactive power as well as ride through capability during fault. It must also be capable to disconnect itself from the grid when islanding event occurred. Lastly, the On/Off Tie inverter is capable of operates in both islanded and grid connected conditions of a microgrid. The earliest written record of the term "inverter" can be traced back to 1925 when D.C. Prince published an article entitled "The Inverter" in GE Review. However, the idea of converting DC to AC experiment was proposed and carryout by Alexanderson from GE in 1920, back then he called this process "inverted rectification". Prince appears to have been borrowing Alexanderson expression of "inverter rectification" and created a single English-language word inverter that has been used since then till present day [2].

Off-grid inverter basically consists of 2 stages of converter, the DC to DC voltage step up converter and DC to AC inverter with voltage PI control and LC filter to produce sine wave output. Each stage has its own challenges and there are many works of literature has been published to address these challenges and research gap for the off-grid inverter. For the first stage, the DC to DC voltage step up conversion is carryout using the push-pull converter topology through a high frequency step up transformer and rectification. The high frequency push-pull converter topology has been commonly used as the first stages for many small to medium commercial off-grid inverter design. The challenges are to step up the low battery DC voltage level with minimum losses, low footprint and weight of the components. There are literatures proposed an interleaving push-pull converter which can produce high output voltage from a very low battery voltage input. The interleaved push-pull converter is a combination of multiple push-pull converters with transformer secondary rectifier connected in series for achieving the desired output voltage level [3-4]. The shortcoming is the cost, footprint and weight of this interleaved push-pull will increase with the number of transformers, switching devices and rectifiers. Another literature proposed to simplify the entire off-grid inverter by using only one stage of push-pull inverter to step up the voltage at switching frequency of $50 \mathrm{or} 60 \mathrm{~Hz}$. This significantly increases the size and weight of the transformer and the AC output waveform is highly distorted and no longer sine wave [5-6]. There are other approaches by utilizing single or dual DC-DC boost converter topology to step the battery voltage to the desired voltage level in place of push-pull topology [7-11]. This approach reduces the use of step up transformer and rectifier stage. However it suffers from low efficiency and voltage magnitude stability to step up battery $12 \mathrm{~V}$ to $350 \mathrm{~V}$ and above. The second stage is the DC to AC inverter where H-Bridge topology with either MOSFET or IGBT switching devices is commonly utilized. A Sinusoidal Pulse Width Modulation (SPWM) is use to switch the H-Bridge with LC filter to produce sinewave AC output waveform [12-13]. A PI feedback control is utilized for voltage or current control. There is literature proposed to have a very high switching frequency of $100 \mathrm{kHz}$ for the push-pull inverter to step up the voltage followed by a $20 \mathrm{kHz}$ SPWM switching frequency to switch the $\mathrm{H}$-Bridge [14]. However, PI feedback control was not included in the off-grid inverter design and high switching frequency suffer from high switching losses. The off-grid inverter feedback control presented in the literatures [15-19] assumed a constant voltage source and multi-level DC link [20-21] is supply to the HBridge which does not reflect the actual inverter operation with battery. The inverter H-Bridge plant and system tracking response were not discuss for the PI controller design [22-27].

In summary the above literatures lack of performance analysis including conversion efficiency, total harmonic distortion and validation with reference to commercial off-grid inverter. The modeling details are not provided to make simulation reproducible. This paper intended to present the modeling of a complete single phase off-grid inverter commonly implements in commercial inverter. It consist of a DC-DC $20 \mathrm{kHz}$ high frequency step up converter and a H-Bridge inverter with $500 \mathrm{~Hz}$ SPWM and voltage PI feedback control.

\section{RESEARCH METHOD}

The entire off-grid inverter model is developed using MATLAB/Simulink platform with Simscape Electrical blocksets. The completed model is then tested and simulate under Simulink environment for performance analysis. The complete overview of the off-grid inverter model in Simulink is shown in Figure 1. It consists of a battery source, DC-DC step up converter, full bridge inverter with voltage PI control and a resistive load. This is the common design use for many small to medium commercial off-grid inverter. The battery model is directly obtained from Simulink Simscape Electrical blockset library and a resistive element is used to represent the inverter load by setting its resistance value. The off-grid inverter model is capable of converting a $48 \mathrm{VDC}$ from a battery source to $230 \mathrm{VAC} 50 \mathrm{~Hz}$ up to $1 \mathrm{~kW}$ power rating. The following sections explain the circuitry model in details. 


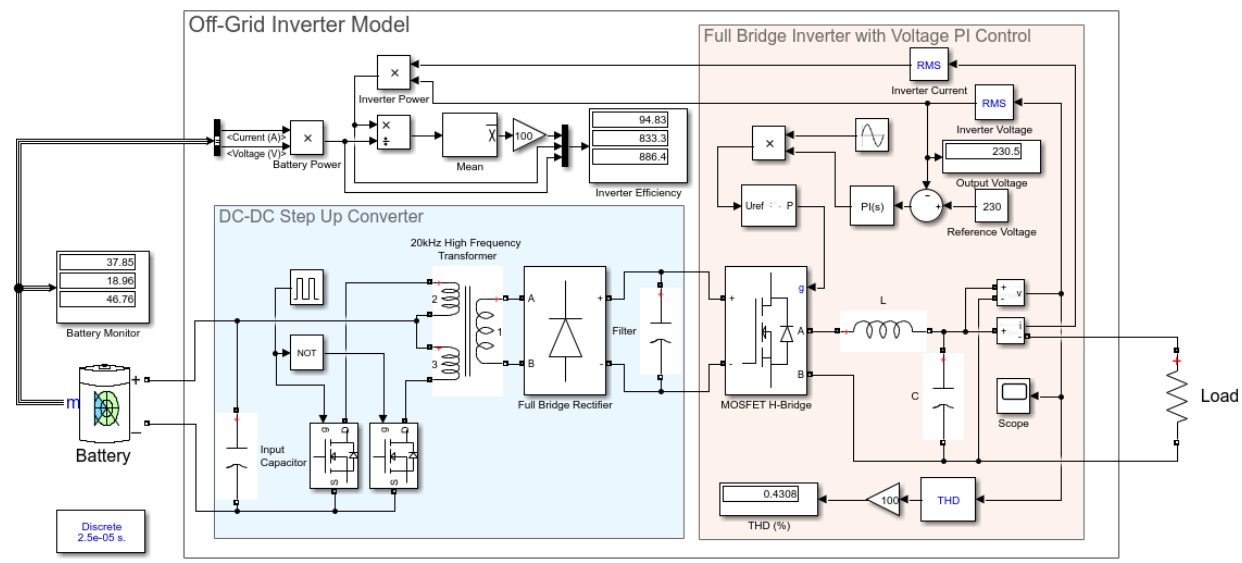

Figure 1. The complete overview of the off-grid inverter model in Simulink

\subsection{DC-DC step Up converter}

The DC-DC step up converter steps up the battery source 48 VDC to 400 VDC. The DC-DC step up converter utilizes the high frequency push-pull converter to converts the battery source 48 VDC to 48 VAC at $20 \mathrm{kHz}$ and step up through a high frequency transformer to $400 \mathrm{VAC}$ and then rectified it back to 400 VDC. The detail circuitry model of the DC-DC step up converter section is shown in Figure 2. The push-pull converter uses two MOSFET switches arrange in push-pull topology connect to the center tap high frequency transformer. The MOSFET $\mathrm{R}_{\text {on }}$ is set to $0.05 \Omega$. The MOSFET is switch by a pulse generator with $20 \mathrm{kHz}$ switching frequency at $50 \%$ duty cycle. The NOT block provide the 1 's complement output of the pulse generator. The two MOSFET in the push-pull topology is switch in a complementary manner to push and pull the current through the center tap transformer to produce $20 \mathrm{kHz}$ AC output. The $2000 \mu \mathrm{F}$ input capacitor serves to smooth out the inrush current to the transformer during switching. The high frequency center tap transformer nominal power and frequency is set to $5 \mathrm{kVA}$ and $20 \mathrm{kHz}$ respectively. The magnetization resistance and inductance of the high frequency step up transformer is set at 5000 and 500 pu respectively. By taking account of the voltage drop across the MOSFET during switching both primary winding 2 and 3 that form the center tap is set to $46 \mathrm{Vrms}$. The secondary winding 1 is set at $400 \mathrm{Vrms}$. The high frequency transformer significantly reduces its physical footprint and weight compared with low frequency transformer with similar power rating. This is a very important criteria for off-grid inverter hardware implementation.

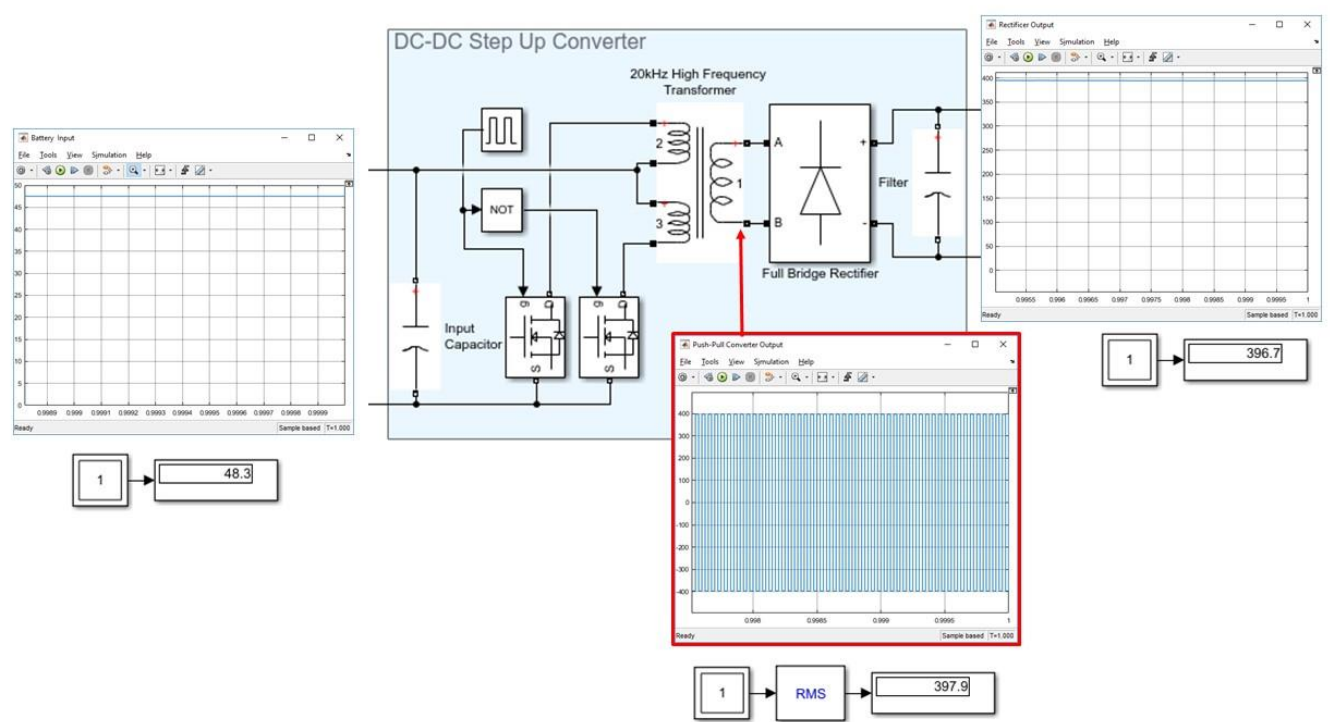

Figure 2. DC-DC step up converter circuit in Simulink 


\subsection{Full bridge inverter with voltage $P I$ control}

The full bridge inverter converts the DC output voltage from the full bridge rectifier to AC sine wave output. The full bridge inverter with voltage PI control in Simulink is shown in Figure 3. The full bridge inverter is implemented using the universal bridge block from the Simulink Simscape Electrical blockset library. In the universal bridge block, the number of the bridge is set to 2 and the power electronic device is set to MOSFET so that the universal block will configure as four MOSFETs H-Bridge circuit. The $\mathrm{H}$-Bridge is switch and driven by Sinusoidal Pulse Width Modulation (SPWM). The SPWM modulator carrier frequency is set to $500 \mathrm{~Hz}$. The output of the $\mathrm{H}$-Bridge is then filtered through a LC low pass filter to produce a sine wave output waveform. The LC low pass filter is designed based on butterworth filter design. The inductor and capacitor are set to $0.1 \mathrm{H}$ and $100 \mu \mathrm{F}$ respectively. The output rms voltage of the inverter is then fed back to a PI controller. The reference voltage for the PI controller is set to 230 Vrms. The output of the PI controller is fed to the SPWM modulator through 2-Level PWM Generator block.

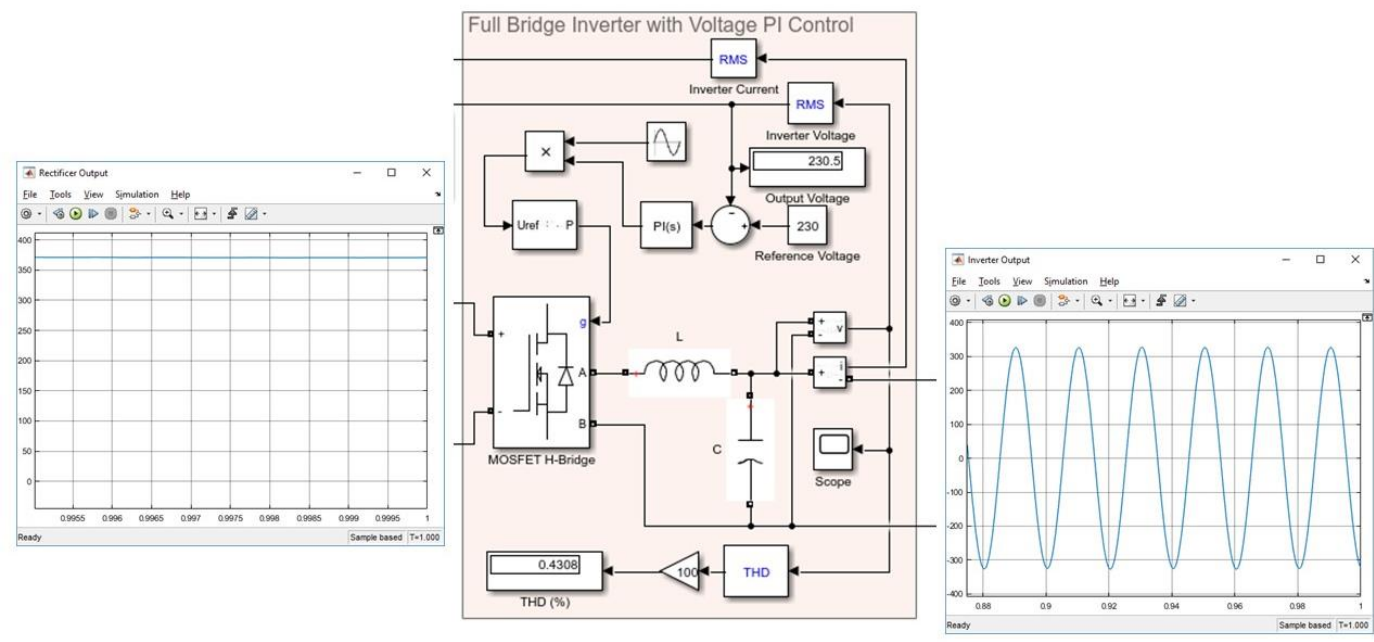

Figure 3. Full bridge inverter with voltage PI control circuit in Simulink

The PI controller gain was determined by the transfer function tuning method available in the PID block. The H-Bridge inverter plant model was identified with the data driven method. Two seconds of input and output data were simulated for model identification. With the availability of the single pole plant model, the PI controller was tuned to track as close as possible with the plant response [28]. With that in mind, the PI controller $\mathrm{Kp}$ and $\mathrm{Ki}$ were set to 0.0041 and 0.0288 respectively. The tracking performance achieved with almost no overshoot and attaining a settling time of $0.46 \mathrm{~s}$. The identified plant model transfer function and tuned tracking response are shown in Figure 4.

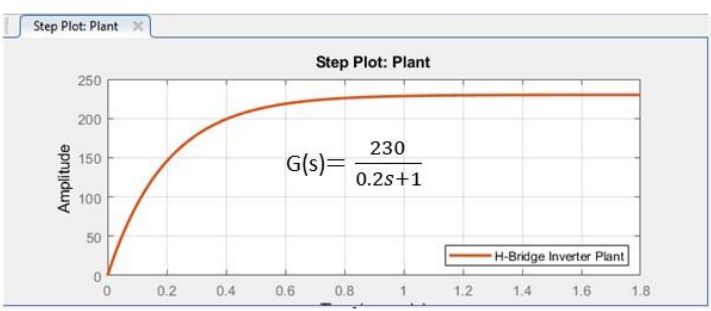

(a)

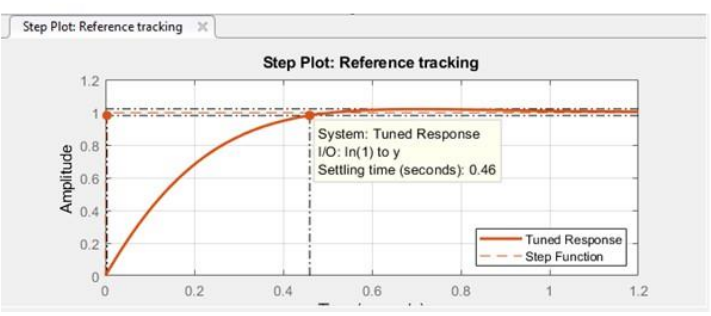

(b)

Figure 4. Plant model transfer function (a) and tuned tracking response (b)

The voltage Total Harmonic Distortion (THD) is the most important indicator to quantify any inverter AC output waveform with respect to ideal pure sinewave. The THD delivered from the grid is strictly governed by electrical utilities around the world. In general, the inverter voltage THD has to be less 
than 5\% from IEC or IEEE standard perspective to be considered acceptable [29-30]. Mathematically the voltage Total Harmonic Distortion can be determined in (1) where $V$ is the voltage magnitude and $n$ is the harmonic order.

$$
T H D_{v}=\sqrt{\frac{\sum_{n=2} V_{n}^{2}}{V_{1}^{2}}}
$$

The instantaneous output voltage THD measurement provides a quick indication of the inverter output waveform performance. It is computes by the THD block based on (1) as shown in Figure 3. The THD block is fed in from the voltage measurement block taken at the output of the inverter. Since the THD block only output from 0 to 1 so a gain block with 100 is required to convert it to percentage.

\section{RESULTS AND DISCUSSION}

The completed off-grid inverter model is simulated in Simulink environment for performance analysis. The Simulink configuration is the most important aspect to ensure the test and simulation can be executed successfully. The Simulink configuration setup is configured to ode23tb (Stiff/TR-BDF2) solver with variable step. The simulation type is set to discrete with a sample time of $2.5 \mu$ ser sample. The following sections detail out the performance analysis of the model including output voltage tracking response and inverter efficiency performance validation with a commercial off-grid inverter.

\subsection{Output voltage tracking stability}

The output voltage tracking determines the off-grid inverter model output voltage stability and the performance of the tuned PI controller to maintain the set output voltage level of $230 \mathrm{~V}$. Figure 5 shows the off-grid inverter model output voltage magnitude tracking stability. It can be clearly seen that the PI controller are able to track the output voltage between $227.2 \mathrm{~V}$ and $232.9 \mathrm{~V}$, which are $-1.22 \%$ and $+1.26 \%$ of $230 \mathrm{~V}$ respectively. In summary, the tuned PI controller are able to track at the average output voltage of $230.4 \mathrm{~V}$ in less than $0.5 \mathrm{~s}$ without any overshoot.

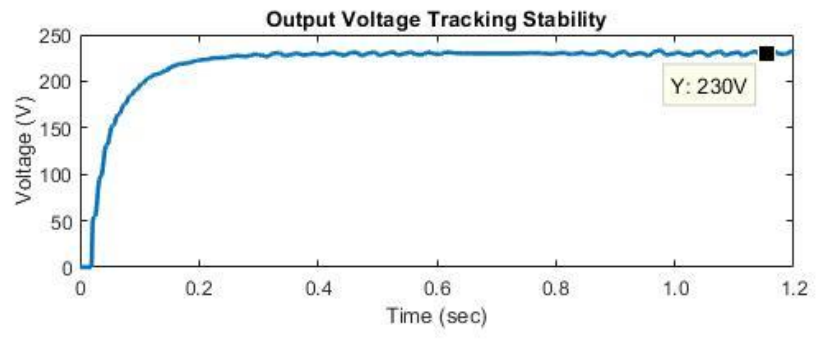

Figure 5. Offgrid inverter model output voltage tracking stability

\subsection{Model performance validation with commercial inverter}

To validate the performance of this Simulink model is comparable with the commercial off-grid inverter. A commercial off-grid inverter is setup with 48 VDC battery source and various AC loads is shown in Figure 6. The commercial off-grid inverter use for validation is from EPEVER SHI1000-42, the specification of the off-grid inverter power rating is $1000 \mathrm{~W}$, THD of $\leq 3 \%$ and efficiency of $\geq 94 \%$. The inverter is set to output $230 \mathrm{~V} 50 \mathrm{~Hz}$. The lead acid $12 \mathrm{~V}$ battery is deep cycle gel type from OUTDO with a capacity of $100 \mathrm{AH}$ and internal resistance of $4 \mathrm{~m} \Omega$ at full charge. The $48 \mathrm{~V}$ battery source consist of eight $12 \mathrm{~V}$ battery connected in series of four batteries and parallel of two series set yield a total $48 \mathrm{~V}$ of $200 \mathrm{AH}$ capacity with a total internal resistance of $8 \mathrm{~m} \Omega$. The AC loads in the validation experiment are $1 \mathrm{HP}$ aircon and ten $100 \mathrm{~W}$ light bulb with dimmer control. The off-grid inverter Simulink model efficiency performance is carryout by simulating the inverter under various load condition ranging from $25 \mathrm{~W}$ to $1000 \mathrm{~W}$ with $230 \mathrm{~V}$ $50 \mathrm{~Hz}$ in Simulink environment. The efficiency can be determined by the ratio of the input power from the battery to the output power to the load as shown in Figure 1. The efficiency display shows the output power, input power and the conversion efficiency with a one second average window through the mean block. 
Similarly, the efficiency performance for the commercial off-grid inverter is carried out by energizing the light bulb loads ranging from $25 \mathrm{~W}$ to $1000 \mathrm{~W}$. The measured input, output power and efficiency are then save as reference for off-grid inverter Simulink model validation.

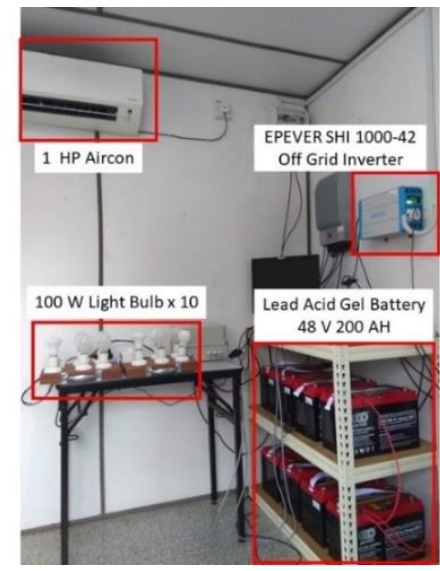

Figure 6. Validation experiment setup with commerical off-grid inverter, battery and AC loads

The conversion efficiency performance validation results are shown in Figure 7. It shows a common characteristic of many commercial inverter efficiency curves. The average efficiency from $500 \mathrm{~W}$ onward which is $50 \%$ of rated capacity for the Simulink model and commercial inverter are $94.8 \%$ and $93.8 \%$ respectively. The efficiency drop significantly at load power less then $100 \mathrm{~W}$, this is simply because the conversion losses in power electronic switching devices became more prominent in low power conversion which is less than $10 \%$ of the inverter rated capacity. The differences in efficiency at less than $100 \mathrm{~W}$ could be possibly caused by different topology, components tolerance and switching losses.

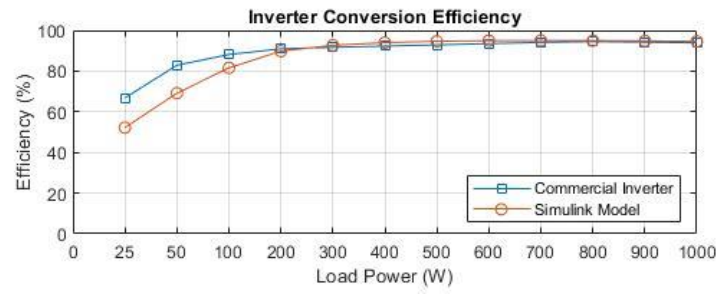

Figure 7. Inverter conversion efficiency performance curve

The overall performance validation experiment begins with recording the commercial off-grid inverter battery input power, battery state of charge and AC output power with $1 \mathrm{HP}$ aircon load set at $26^{\circ} \mathrm{C}$ running On and Off within the time interval of 60 mins. The recorded data is then saved as reference of the off-grid inverter Simulink model validation. The same battery source and AC load conditions are then applied to the off-grid Simulink model for 60 mins. The simulated data is then compared with the recorded data for validation and performance analysis. Figure 8 shows the overall validation results of output power, efficiency and battery state of charge. It can be clearly see that the power output of the model and commercial inverter almost overlapped with each other indicating the model simulation output power is close to the commercial off-grid inverter data. The conversion efficiency performance of the off-grid inverter model developed in Simulink is comparable with the commercial off-grid inverter recorded data near rated power which is around $900 \mathrm{~W}$ with an average efficiency around $94 \%$ which matches the commercial inverter product specification. When the aircon load is turn off, the load power is about $25 \mathrm{~W}$ where the average efficiency is about $50 \%$ which matches the efficiency performance curve shown in Figure 7, as explain earlier the differences in efficiency at $25 \mathrm{~W}$ of around $15 \%$ could be possibly caused by different topology, components tolerance and switching losses. The Battery State of Charge (SOC) discharge rate also shows a comparable trend with the real battery with about $1 \%$ of SOC difference at the end of the simulated 
data. The battery SOC oscillation is caused by the charge controller charging the battery when the aircon load is turn off. The validation experiment took place in the evening around 18:00 where there are still some evening sunlight to generate power from the photovoltaic panel to charge the battery. The slightly higher discharge rate of the real battery could be possibly caused by the aging of the battery and the different in SOC measurement method.

The off-grid inverter Simulink model results presented in this paper are fully reproducible, with that in mind the model in MATLAB/Simulink presented in this paper is made available by the authors for the reader to download at Mathworks official MATLAB Central File Exchange. https://www.mathworks.com/matlabcentral/fileexchange/73116-off-grid-inverter-model
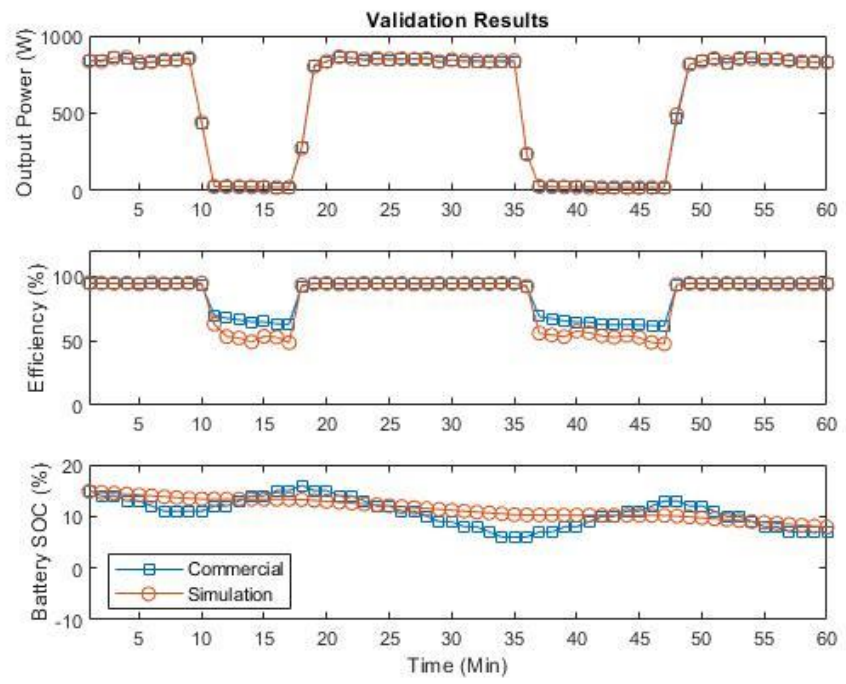

Figure 8. Overall Performance Validation between Simulink Model and Commercial Inverter

\section{CONCLUSION}

A detail circuitry modeling of an off-grid inverter model in Simulink is presented. Each stage of the off-grid inverter modeling are clearly illustrated and are fully reproducible. The off-grid inverter uses a 20 $\mathrm{kHz}$ high frequency transformer push-pull inverter to step up the battery 48 VDC to $400 \mathrm{VAC}$ and convert back to DC through a full bridge rectifier. The $400 \mathrm{VDC}$ is then converted to $230 \mathrm{VAC} 50 \mathrm{~Hz}$ sinewave through H-bridge inverter with Sinusoidal Pulse Width Modulation and LC filter. The output voltage is control and maintains by PI feedback control. The off-grid inverter model is capable of converting a $48 \mathrm{~V}$ from a lead acid battery source to $230 \mathrm{~V} 50 \mathrm{~Hz}$ up to a power rating of $1000 \mathrm{~W}$. It achieved an average conversion efficiency of $\geq 94 \%$ and produces sinewave output waveform with THD of less than $1 \%$. The performance of the Simulink model is also validated with the commercial off-grid inverter. The Simulink model presented can be flexibly changed to meet the commercial inverter with similar topology. This model contributes to assist small to medium standalone system load and battery sizing design with greater accuracy.

\section{ACKNOWLEDGEMENTS}

The authors would like to acknowledge the PSIF grant Proj-In-FETBE-040 and conference funding CONF-NATN-FETBE-207 support from UCSI University research management unit CERVIE so that the research and publication of this work are made possible.

\section{REFERENCES}

[1] "Renewables 2019 Global Status Report”, Renewables Now (REN21). pp. 40. 2019

[2] E.L. Owen, "Origin of the inverter". IEEE Industry Applications Magazine, vol. 2, no. 1, pp. 64-66, 1996.

[3] Wang, J., Li, J. Zhang, W, "Interleaved push-pull converter with very low input and high output", 2nd Conference on Power Electronics and Intelligent Transportation System, PEITS, pp. 247-249, 2009.

[4] Mandeep Anand, Rahul P.P, Eldhose K.P, Linss T Alex, "Design of Interleaved Push Pull Converter for Photovoltaic Systems", IOSR Journal of Engineering, pp. 73-80, 2018. 
[5] Shema, S. S., Daut, I., Syafawati, A. N., Irwanto, M., \& Shatri, C, "Simulation of push-pull inverter for photovoltaic applications via multisim", 5th International Power Engineering and Optimization Conference, PEOCO, pp. 103-106, 2011.

[6] Abiodun Alani Ogunseye, Daniel Ogheneovo Johnson, "Development of a Microcontroller-Based 6/12/18/24V Power Inverter Circuit", Journal of Communications Technology, Electronics and Computer Science, vol. 10, pp. 19-23. 2016.

[7] Mao, L., Chen, J., Deng, Y., \& Wang, C, "A Novel Photovoltaic Off-grid Inverter Based on Boost Converter", International Power, Electronics and Materials Engineering Conference, IPEMEC, pp. 166-169, 2015.

[8] Bhutada, S., \& Nigam, S. R, "Single Phase PV Inverter Applying a Dual Boost Technology", International Journal of Applied Power Engineering (IJAPE), vol. 5, pp. 95-102, 2016.

[9] Swapnil Shende, Shubhanar Potdar, Prati Suryawanshi, Sankalp Pund, "Analysis of Single Phase Inverter for Standalone Residential Load Using Solar Photovoltaic Arrays", International Journal of Innovative Research in Science Engineering and Technology, vol. 5, pp. 19239-19248, 2018.

[10] Thandar Aung, Tun Lin Naing, "DC-Link Voltage Control of DC-DC Boost Converter-Inverter System with PI Controller", International Journal of Electrical and Computer Engineering, vol. 12. Pp. 848-856, 2018.

[11] Md. Khurshedul Islam, Md. Mizanur Rahman, Md. Fazle Rabbi, "Transformer less, Lower THD and Highly Efficient Inverter System", 3rd International Conference on Advances in Electrical Engineering, 2015.

[12] B. Ismail, S. Taib, A.R. Mohd Saad, M. Isa, C.M. Hadzer, "Development of a Single Phase SPWM Microcontroller Based Inverter", 1st International Power and Energy Conference, PECon 2006.

[13] Sandeep Phogat, "Analysis of Single-Phase SPWM Inverter", International Journal of Science and Research, vol. 3, pp. 1793-1798, 2014.

[14] Nasrudin Abd. Rahim, Mohamad Fathi Bin Mohamad Elias, Jafferi Bin Jamaludin, "Design and Implementation of a Stand-Alone Micro-Inverter with Push-Pull DC/DC Power Converter", 4th IET Clean Energy and Technology Conference CEAT 2016.

[15] Ali Algaddafi, Neil Brown, Gammon Rupert, Jubran Al-Shahrani, "Modelling a Stand-Alone Inverter and Comparing the Power Quality of the National Grid with Off-Grid System", IEIE Transactions on Smart Processing and Computing, vol. 5, pp. 35-42, 2016.

[16] Tracy Chai Anak Ajot, Suriana Salimin, Roziah Aziz, "Application of PI Current Controller in Single Phase System Connected to Non Linear Load”, IOP Conf. Series: Materials Science and Engineering 226, 2017.

[17] Ali Algaddafi, Neil Brown, Rupert Gammon, Saud A Altuwayjiri, Mohammed Alghamdi, "Improving Off-Grid PV System Power Quality, and Comparing with Grid Power Quality", International Conference on Electronics, Information, and Communications ICEIC 2016.

[18] Omar Diouri, Najia Es-Sbai, Fatima Errahimi, Ahmed Gaga, Chakib Alaoui, "Control of Single Phase Inverter using Back-Stepping in Standalone Mode", International Conference on Wireless Technologies, Embedded and Intelligent System, 2019.

[19] Jose Luis Mata Ledesma, Oscar Carranza Castillo, Ruben Ortega Gonzalez, Jaime Jose Rodriguez Rivas, Daniel Memije Garduno, "Single-phase Standalone Inverter with an Integrated Control Structure", IEEE 28th International Symposium on Industrial Electronics, 2019.

[20] Ramkumar L Maurya, Mini Rajeev, "Implementation of Multilevel DC-Link Inverter for Standalone Application", International Conference on Nascent Technologies in Engineering, 2017.

[21] M. Kanimozhi, R. Ramaprabha, "Design of 500W Standalone Photovoltaic System with Reduced Switch Count Multilevel Inverter", Trends in Industrial Measurement and Automation, 2017.

[22] Ali Algaddafi, "Stand-alone Inverter Reviews, Models and Tests the exist System in Term of the Power Quality, and Suggestions to Design it", Advances in Science, Technology and Engineering Systems Journal, vol. 1, pp, 3441, 2016.

[23] Sunil Govinda Solanki, Manickam Ramasamy, Shahid Manzoor, Uthaya Kumar Rostem Ganesalingam, "Design \& Development for OFF grid Solar Inverter", IEEE 4h International Symposium in Robotics and Manufacturing Automation ROMA 2018

[24] Tow Leong Tiang, Dahaman Ishak, "Modeling and Simulation of Deadbeat-Based PI Controller in a Single-Phase H-Bridge Inverter for Stand-alone Applications", Turkish Journal of Electrical Engineering \& Computer Sciences, vol. 22, pp. 43-56, 2014.

[25] Chitra L, Abinaya S, Muthuselvi K, Arulkumar S., "Analysis and Simulation of Standalone PV Based Inverter", International Conference on Innovations in Information, Embedded and Communication Systems ICIIECS 2017

[26] Linda Hassaine, Mohamed Rida Bengourina, "Control Technique for Single Phase Inverter Photovoltaic System Connected to the Grid”, Energy Report, 2019.

[27] Narendra Kumar, Dheeraj Joshi, Sachin Singhal, "Design and Performance Analysis of a Single Phase PWM Inverter", 6th IEEE Power India International Conference PIICON, 2014.

[28] J.C. Basilio, S.R. Matos, "Design of PI and PID Controllers with Transient Performance Specification", IEEE Transactions on Education, vol. 45, pp. 364-370, 2002.

[29] R.A. Barr, V.J. Gosbell, "Power System Harmonic Voltage Limits for the Future", 16th International Conference on Harmonics and Quality of Power (ICHQP), 2014.

[30] E. Gunther, "Harmonic and Interharmonic Measurement According to IEEE 519 and IEC 61000-4-7", IEEE/PES Transmission and Distribution Conference and Exhibition, 2006. 